\title{
Denosumab: a new option in the treatment of bone metastases from urological cancers
}

This article was published in the following Dove Press journal:

OncoTargets and Therapy

20 September 2012

Number of times this article has been viewed

\section{Takeshi Yuasa \\ Shinya Yamamoto \\ Shinji Urakami \\ Iwao Fukui \\ Junji Yonese}

Department of Urology, Cancer Institute Hospital, Japanese Foundation for Cancer Research, Ariake, Tokyo, Japan
Correspondence: Takeshi Yuasa Department of Urology, Cancer Institute Hospital, Japanese Foundation for Cancer Research, Ariake, Tokyo,

135-8550, Japan

$\mathrm{Tel}+8 \mathrm{I} 35200$ III

Fax +8I 35700343

Email takeshi.yuasa@jfcr.or.jp

\begin{abstract}
Bone metastases often create serious clinical problems: they lead to poor performance status due to pathologic fractures, spinal cord compression and intractable pain, commonly referred to as skeletal-related events. The receptor activator of nuclear factor- $\kappa \mathrm{B}$ (RANK), the RANK ligand (RANKL), and osteoprotegerin, a decoy receptor for RANK, regulate osteoclastogenesis and may play a key role in bone metastasis. Denosumab (XGEVA; Amgen, Thousand Oaks, CA), a fully human monoclonal antibody that binds to and neutralizes RANKL, inhibits osteoclast function, prevents generalized bone resorption and local bone destruction, and has become a therapeutic option for preventing or delaying first on-study skeletal-related events in various malignancies. In the context of urological cancer, three main Phase III clinical studies have been published in prostate cancer. This article provides a brief overview of the characteristics of bone metastasis in urological cancers, reviews the mechanisms of bone metastasis, including the RANK/RANKL/osteoprotegerin axis, the current standard of care, zoledronic acid, and describes the efficacy of the novel bone-targeted agent denosumab in bone metastasis. Denosumab is emerging as a key therapeutic option in the treatment of bone metastases from urological cancers.
\end{abstract}

Keywords: bone metastasis, denosumab, prostate cancer, renal cell cancer, urothelial cancer, zoledronic acid

\section{Introduction}

Bone is a major metastatic site for many solid tumors. Indeed, after lung and liver, bone is the most common metastatic site for up to $70 \%$ of advanced breast and prostate cancer and for approximately $15 \%$ to $30 \%$ of lung, colon, gastric, bladder, uterus, rectal, thyroid cancer, or renal cell cancer (RCC). ${ }^{1-3}$ Bone seems to provide an ideal microenvironment in which metastatic cancer cells can thrive. When luciferase-labeled cancer cells are introduced into animals by intracardiac injection, they initially appear as diffuse photon accumulations throughout the body, become completely undetectable after 6 hours, and subsequently form bone metastases (Figure 1A). Bone metastases often create serious clinical problems; they lead to poor performance status due to pathologic fractures, spinal cord compression, and intractable pain, commonly referred to as skeletal-related events (SREs)., ${ }^{2,4}$ The third-generation bisphosphonate, zoledronic acid (ZOL, Zometa ${ }^{\circledR}$; Novartis Pharma AG, Basel, Switzerland), an inhibitor of bone resorption, is the current standard of care for preventing SREs associated with bone metastases and is the only agent that has demonstrated statistically significant reductions of SREs due to metastatic bone lesions in various cancers. ${ }^{5-8}$ 

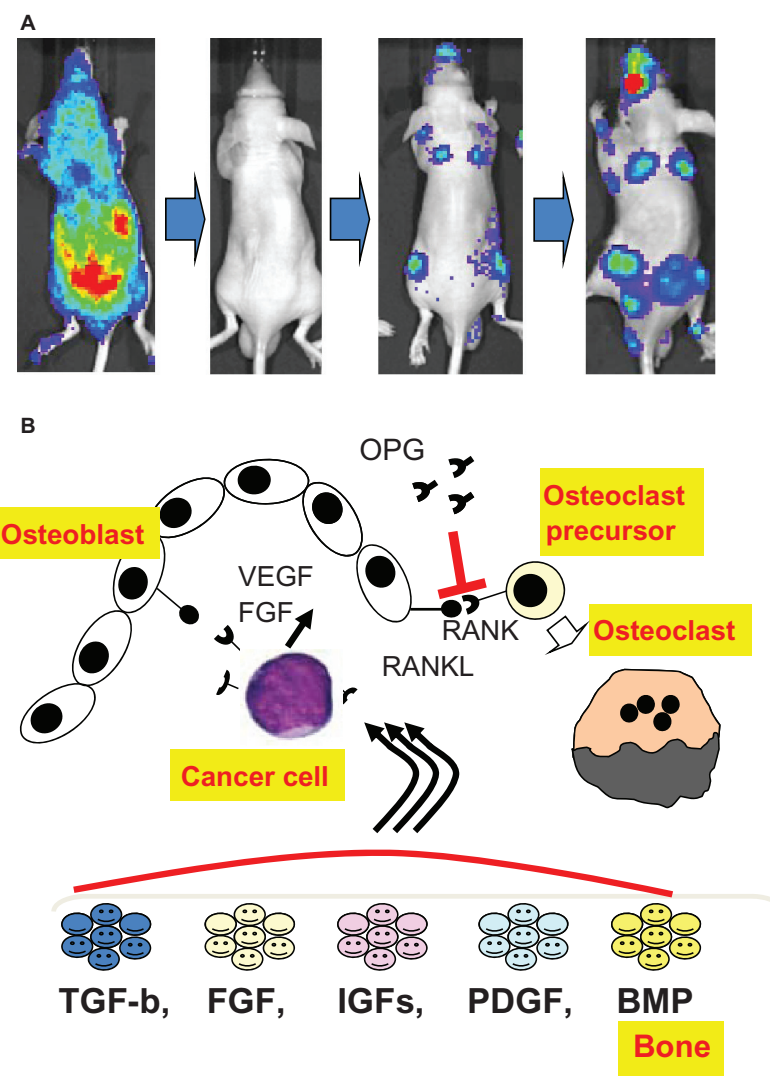

Figure I Bone as an ideal site for metastatic cancer cells. After injection into the left ventricle, luciferase-labeled cancer cells initially appeared as diffuse photon accumulations throughout the body, were completely undetectable after 6 hours, and subsequently developed bone metastases (A). Schematic representation of the interplay between metastatic cancer cells, osteoblasts and osteoclasts in bone, and of the function of the RANK/RANKL/OPG axis. Various growth factors are released when osteoclasts absorb bone that provides fertile ground for cancer cells to grow. Cancer cells activate osteoblasts to increase the production of RANKL. RANKL then interacts with RANK and promotes differentiation into mature osteoclasts. OPG acts as an inhibitor of osteoclastogenesis by serving as a decoy receptor for RANKL (B). RANK: receptor activator of nuclear factor $\kappa B$.

Abbreviations: BMP, bone morphogenetic proteins; FGF, fibroblast growth factor; IGFs, insulin-like growth factors I and II; OPG, osteoprotegerin; PDGF, plateletderived growth factor; RANKL, RANK ligand; TGF $\beta$, transforming growth factor $\beta$.

The receptor activator of nuclear factor- $\mathrm{KB}$ (RANK, also called tumor necrosis factor receptor superfamily member 11A; TNFRSF11A), the RANK ligand (RANKL, also called the tumor necrosis factor ligand superfamily member 11; TNFSF11), and osteoprotegerin (OPG, also called TNFRSF11B) are the major regulators of bone metabolism. ${ }^{9} 10$ The RANK/RANKL/OPG axis regulates osteoclastogenesis and may play a key role in bone metastasis. The function of the RANK/RANKL/OPG axis and the interplay between metastatic cells, osteoblasts, and osteoclasts in bone are summarized in Figure 1B.

Denosumab (XGEVA; Amgen, Thousand Oaks, CA), a novel agent targeting bone resorption, is a fully human monoclonal antibody that binds to and neutralizes RANKL, thereby inhibiting osteoclast function and preventing generalized bone resorption and local bone destruction. ${ }^{11}$ In Phase III clinical trials, denosumab was demonstrated to be noninferior (trending to superior) to zoledronic acid in preventing or delaying first on-study SREs in patients with bone dissemination or myeloma. ${ }^{11,12}$ Therefore, denosumab is emerging as a novel anti-resorptive clinical agent for use in bone metastasis. This article provides a brief overview of the characteristics of bone metastasis in urological cancers, including renal cell, urothelial, and prostate cancer, summarizes mechanisms of dissemination to bone, and presents the mechanism of action and efficacy of denosumab in the clinical management of urological cancer bone metastasis.

\section{Characteristics of urological cancer bone metastasis \\ Renal cell cancer}

Bone is a common metastatic site in RCC, second only to lung, with estimates of frequency ranging from $24 \%$ to $51 \% \cdot{ }^{13-15} \mathrm{RCC}$ bone metastasis often has a pseudo-negative appearance on a bone scan, is mostly osteolytic and generally aggressive, and results in rapid bone destruction. ${ }^{16}$ Upon diagnosis of RCC bone metastasis, since the current standard technique for diagnosing bone metastasis is radionuclide 99 m-technetium pyrophosphate scintigraphy, which identifies sites of active bone formation, RCC bone lesions often have a pseudo-negative appearance (Figure 2A). ${ }^{15,16}$ In a study of patients with RCC bone metastasis, Zekri et al reported that the frequency of lesions with osteolytic, osteoblastic, and mixed radiographic appearance was approximately $71 \%, 18 \%$, and $11 \%$, respectively. ${ }^{17}$ Aggressive osteolysis also often causes significant morbidity from the resulting SREs, and radiotherapy for bone pain, hypercalcemia, and pathological fractures create serious problems for patients and often lead to poor performance status. ${ }^{15-17}$ Zekri et al also reported the SREs experienced by 84 patients with bone metastases with a skeletal morbidity rate (number of SREs/ patient/year) between 2.5 and 4.0 during the first year. ${ }^{17}$ In their report, 29\% developed hypercalcemia, ${ }^{17}$ attributable to tumor production of cytokines and ectopic polypeptides including parathyroid hormone-related peptide. Table 1 presents a summary of the incidence of SREs and efficacy of zoledronic acid in patients with prostate, breast, or renal cell cancers based on Phase III clinical trials. ${ }^{5,7,8}$ Although the study period was different for each trial, the morbidity of RCC bone metastasis was comparable to that of prostate and breast cancer bone metastasis, yet the morbidity of RCC bone 
A

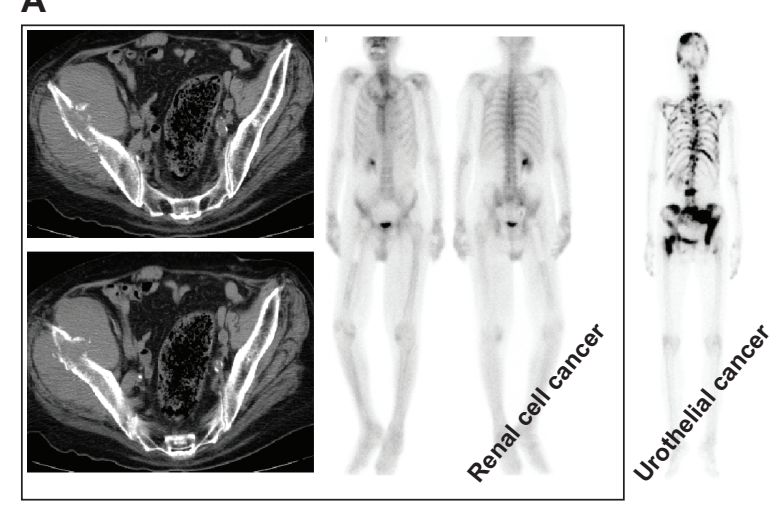

B

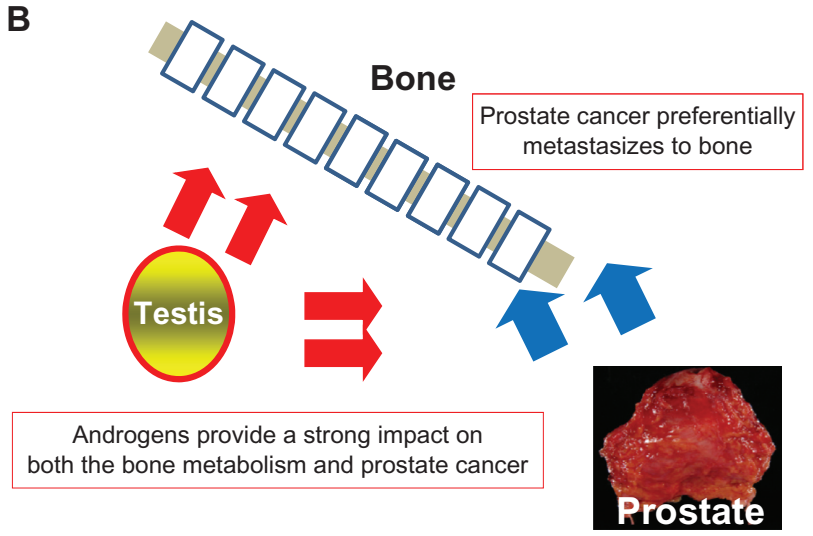

Figure 2 Characteristics of urological cancer skeletal lesions. Characteristics of bone metastasis from renal cell cancer. The bulky bone metastatic lesion, which was demonstrated by abdominal CT-scan, has a negative appearance by bone scan. Typical bone metastatic lesions from urothelial cancer, which have a positive appearance by bone scan, are shown on the right side $(\mathbf{A})$. Schematic representation of the interplay between prostate cancer, bone and testosterone (B).

Abbreviation: CT, computed tomography.

metastasis receives considerably less attention than that of breast and prostate cancer bone metastasis. Despite a higher incidence of bone lesions, a longer survival is observed after diagnosis of dissemination to bone. . $^{5,7,8}$

The distribution of RCC skeletal metastasis was predominantly to the axial skeleton, affecting the pelvis in $48 \%$, the spine in $34 \%$, and the ribs in $48 \%$ of cases. ${ }^{17}$ These results are consistent with our recent report in which involvement of the pelvis, spine, and ribs was observed in
$27 \%, 48 \%$, and $48 \%$ of cases, respectively. ${ }^{15}$ In our study, lower extremities were also frequently involved (37\%). ${ }^{15}$ To avoid pathologic fracture and/or intense pain, we often recommend surgical treatment and/or radiation therapy for metastatic lesions, including those of the pelvis, spine, and extremities. ${ }^{15}$

Although it would appear to predispose toward poor prognosis, the prognosis of RCC bone metastasis is controversial. ${ }^{18-21}$ Neither of two large retrospective studies identified bone metastasis as an independent prognostic factor. ${ }^{18,21}$ Recently, we reported treatment outcomes in RCC patients with bone metastasis at our institution. ${ }^{15}$ Among 214 RCC patients with metastasis, 71 patients $(33 \%)$ were found to have bone metastases at the time of the initial diagnosis of metastasis..$^{15}$ The estimated median overall survival from the time of diagnosis of bone metastasis was 27.7 months and the probabilities of patients surviving 1 year, 2 years, and 5 years were $63.7 \%, 52.2 \%$, and $19.3 \%$, respectively. ${ }^{15}$ These observations are comparable to other metastatic sites in RCC.

\section{Urothelial cancer}

Bladder cancer is the most common urothelial cancer, followed by renal, pelvic, and ureteral cancer, and is the fourth most common solid malignancy in males in the United States. ${ }^{22}$ It is estimated that in 2012, there will be 73,510 new cases and 14,880 deaths from bladder cancer in the United States. ${ }^{22}$ Although $70 \%$ of bladder cancers are superficial at presentation and can be managed by transurethral resection, $60 \%$ to $70 \%$ of superficial tumors recur and $20 \%$ to $30 \%$ of recurrent disease progresses to a higher stage or grade..$^{23,24}$ Radical cystectomy is the standard and most effective treatment for operable invasive bladder cancer; ${ }^{24,25}$ however, at initial diagnosis, one fifth of bladder cancer patients exhibit visceral metastasis and up to half of the remaining patients eventually develop invasive cancer and distant metastases. ${ }^{24,26}$ Chemotherapy with a combination of methotrexate, vinblastine, doxorubicin, and cisplatin or

Table I Comparison of skeletal-related events in various cancers in zoledronic acid Phase III clinical studies

\begin{tabular}{|c|c|c|c|c|c|c|c|c|c|}
\hline \multirow[t]{2}{*}{ Cancer } & \multirow[t]{2}{*}{ Study period } & \multirow[t]{2}{*}{ Agent } & \multirow[t]{2}{*}{ Number } & \multicolumn{3}{|c|}{ Skeletal-related events (\%) } & \multirow[t]{2}{*}{ Surgery } & \multirow[t]{2}{*}{ Radiation } & \multirow[t]{2}{*}{ Hypercalcemia } \\
\hline & & & & ALL & $\begin{array}{l}\text { Bone } \\
\text { fracture }\end{array}$ & $\begin{array}{l}\text { Spinal } \\
\text { compression }\end{array}$ & & & \\
\hline \multirow[t]{2}{*}{ Renal cancer } & 21 months & Zoledronic acid & 27 & 37 & 15 & 4 & II & 37 & 0 \\
\hline & & Placebo & 19 & 74 & 63 & II & 21 & 63 & 0 \\
\hline \multirow[t]{2}{*}{ Prostate cancer } & 24 months & Zoledronic acid & 214 & 38 & 17 & 4 & 6 & 26 & 0 \\
\hline & & Placebo & 208 & 49 & 25 & 8 & 7 & 33 & I \\
\hline \multirow[t]{2}{*}{ Breast cancer } & 12 months & Zoledronic acid & 114 & 30 & 25 & 4 & 0 & 9 & 3 \\
\hline & & Placebo & 113 & 50 & 39 & 12 & I & 18 & 9 \\
\hline
\end{tabular}


gemcitabine and cisplatin is the common therapeutic option for distant metastases. ${ }^{23,25,26}$ Bone is the most common visceral metastatic site for bladder cancer, followed by lung and liver. ${ }^{27}$ Although bladder cancer is chemosensitive, most deaths from bladder cancer are caused by invasion and subsequent metastases that are resistant to conventional chemotherapy. ${ }^{26,28} \mathrm{We}$ and others pointed out that visceral metastases, including bone metastases, were predictors of poor prognosis. ${ }^{29,30}$ Novel therapeutic options are needed to improve outcome in advanced bladder cancer.

\section{Prostate cancer}

Prostate cancer has a very high proclivity for metastasizing to bone. Even at the initial diagnosis of prostate cancer, 24\% of patients have metastases as determined by a bone scan. ${ }^{31,32}$ According to the Prostate Cancer Clinical Trials Working Group 2, approximately $90 \%$ of patients with castrationresistant prostate cancer develop bone metastasis. ${ }^{33}$ The presence or absence of bone metastases is one of the most important factors influencing the selection of therapy in prostate cancer.

In 2004, two landmark trials, TAX 327 and SWOG 99-16, showed for the first time that docetaxel, a microtubuletargeted tubulin-polymerizing agent, improved survival in metastatic castration-resistant prostate cancer. ${ }^{34,35}$ Zoledronic acid is a highly potent nitrogen-containing bisphosphonate shown to reduce skeletal complications in patients with bone metastases arising from various solid cancers, including prostate cancer. ${ }^{36}$ Accumulated evidence has revealed that zoledronic acid and taxoids act synergistically or additively in inhibiting the growth of various malignancies, including leukemia, lung cancer, bladder cancer, breast cancer, and prostate cancer. ${ }^{36-40}$ Thus, the combination of docetaxel, prednisolone, and zoledronic acid is the current mainstay of treatment for castration-resistant prostate cancer and bone metastasis.

In addition to the high prevalence of bone metastasis, treatment-induced bone loss is typically seen in patients undergoing androgen-deprivation therapy (ADT). ${ }^{41-43}$ ADT has been the standard treatment for metastatic prostate cancer since Huggins and Hodges first reported it in 1941. ${ }^{44}$ Currently, ADT is also frequently employed in the nonmetastatic setting, either for aging men with local disease or for biochemical failure after prostatectomy or radiation therapy. ${ }^{45,46}$

ADT is associated with anemia, weight gain, insulin resistance, ischemic heart disease, hypogonadism, and increasing bone resorption. ${ }^{31,47}$ Of these ADT complications, increasing bone resorption is of particular concern because it may lead to osteoporosis and bone fractures. ${ }^{41,48}$ A number of studies have shown that ADT-treated patients suffer from bone loss and skeletal-related adverse events, ${ }^{49-52}$ and a recent clinical report disclosed a negative correlation between skeletal fractures and overall survival in ADTtreated patients. ${ }^{53}$ These observations have led to the suggestion that clinicians should be alert to the impact of ADT on bone mineral density and should strive to prevent bone loss. The survival of patients with prostate cancer and bone metastasis is commonly longer than that of patients with other malignant tumors. Therefore, management of bone metastasis and bone metabolism plays important roles in prostate cancer therapy. A schematic representation of the interplay between prostate cancer, bone, and testosterone is shown in Figure 2B.

\section{Mechanism of bone metastasis}

More than 100 years ago, Stephen Paget described the "seed and soil" hypothesis in which seeds of metastatic cancer cells preferentially settle in the soil of the bone matrix. ${ }^{44}$ Bone is an abundant repository for immobilized growth factors, including transforming growth factor $\beta$, fibroblast growth factor, insulin-like growth factors I and II, plateletderived growth factor, and bone morphogenetic proteins (Figure 1B). ${ }^{1,16,36}$ When osteoclasts absorb bone by secreting protons and proteases, growth factors are released that provide fertile ground for cancer cells to grow. As described earlier, bone provides an ideal microenvironment in which metastatic cancer cells can thrive (Figure 1A and B).

Bone-metastasizing cancer cells do not directly activate osteoclasts. They activate stromal cells/osteoblasts through parathyroid hormone receptors to increase the production of RANKL, which plays a central role in osteoclast differentiation and activation. ${ }^{1-3}$ RANKL then interacts with RANK expressed in hematopoietic osteoclast precursors and promotes differentiation into mature osteoclasts. ${ }^{9-11}$ The interaction between RANK and its ligand RANKL plays an important role in osteoclastogenesis. RANKL is a cytokine produced by osteoblasts that stimulates osteoclast activity and inhibits osteoclast apoptosis by binding to its receptor RANK, which is expressed on osteoclasts and their precursors. ${ }^{1,9-11}$ In contrast, OPG, which is expressed by many tissues and cells including osteoblasts, acts as an inhibitor of osteoclastogenesis by serving as a decoy receptor for RANKL. ${ }^{1,9}$ Consequently, the RANK/RANKL/ OPG axis regulates osteoclastogenesis and may perform a key role in bone metastasis. The function of the RANK/ 
RANKL/OPG axis and the interplay between metastatic cells, osteoblasts, and osteoclasts in bone are summarized in Figure 1B.

\section{The RANK/RANKL/OPG axis}

We and others demonstrated the potential therapeutic modulation of the RANK/RANKL/OPG axis. ${ }^{54-56}$ In RCC, Mikami et al demonstrated a positive correlation between RANKL expression level, primary tumor stage, and presence of distant metastasis, and elevated RANKL and RANK and low OPG expression was a significant and independent predictor of recurrence, bone metastasis and poor prognosis. ${ }^{54}$ In addition, recombinant RANKL protein could stimulate the migration of the clear cell RCC cell line Caki-1 in vitro, and this enhanced migration could be inhibited by recombinant OPG protein. ${ }^{54}$ They concluded that the RANK/RANKL/OPG axis was not only involved in RCC bone metastasis but was also involved in metastasis to other organs through the stimulation of cancer cell migration. ${ }^{54}$

In prostate cancer, the expression of RANKL, RANK, and OPG was found to be low in normal cells and markedly elevated in prostate cancer cell lines. ${ }^{55}$ The frequency of expression of RANKL, RANK, and OPG was significantly higher in metastatic prostate cancer than in organ-confined cancer. In addition, the observed increased expression of RANKL, RANK, and OPG correlated with Gleason score, TNM stage, androgen status and serum prostate-specific antigen levels in patients. ${ }^{55}$ The authors concluded that the expression of RANKL, RANK, and OPG correlated with more aggressive, advanced, metastatic prostate carcinoma, suggesting their potential utility in the diagnosis, prognosis, and therapy of prostate cancer. ${ }^{55}$

We evaluated the significance of $O P G$ gene polymorphisms in prostate cancer progression. ${ }^{56}$ The presence of the variant $C$ allele of the $O P G 950 T / C$ polymorphism in the promoter region of $O P G$ may have a considerable protective effect against bone metastasis or disease progression. ${ }^{56}$ In addition, the analysis of metastatic prostate cancer patients (stage D) revealed that the $T$ allele of the OPG $950 \mathrm{~T} / \mathrm{C}$ polymorphism was an independent risk factor, predicting short survival compared to the $C$ allele, according to Cox proportional hazard regression analysis $(P=0.031) .{ }^{56}$ The $C$ allele of the $950 \mathrm{~T} / \mathrm{C}$ polymorphism was associated with high bone marrow density, suggesting that OPG can function effectively to prevent the RANK/RANKL osteolytic signal. ${ }^{56}$ Therefore, the RANK/RANKL/OPG axis may regulate the development of prostate cancer metastasis by modulating bone metabolism.

\section{Zoledronic acid, a novel bisphosphonate, in urological cancer bone metastasis}

Zoledronic acid (Zometa ${ }^{\circledR}$; Novartis Pharma AG), a thirdgeneration bisphosphonate, has the strongest inhibitory activity against bone resorption and is the only bisphosphonate with demonstrated statistically significant reduction of SREs due to metastatic bone lesions in various cancers. ${ }^{16,36,57}$ Zoledronic acid had been the only treatment option for preventing SREs in patients with bone metastasis. ${ }^{16,36,57}$ Bisphosphonates exhibit a high affinity for calcified matrices, such as hydroxyapatite, in bone, ${ }^{16,34,55}$ and they decrease the recruitment, proliferation, and differentiation of pre-osteoclasts, their adhesion to the mineralized matrix, and the resorptive activity of mature osteoclasts. ${ }^{16,36,57}$ Bisphosphonates, both nonamino-bisphosphonates and amino-bisphosphonates, also promote the induction of apoptosis in osteoclasts. ${ }^{16,36,57}$ In a randomized, placebocontrolled trial of zoledronic acid in hormone-refractory metastatic prostate cancer, a greater proportion of patients who received placebo had SREs compared to those who received zoledronic acid at $4 \mathrm{mg}$ (44.2\% vs $33.2 \%$; $P=0.021){ }^{5}$ The median time to first SRE was 321 days in patients who received placebo but SRE was not reached in patients who received zoledronic acid at $4 \mathrm{mg}(P=0.011) .^{5}$ The pain and analgesic scores were higher in patients who received placebo than in patients who received zoledronic acid. ${ }^{5}$ Although there were no differences in disease progression, performance status, or quality-of-life scores between the groups, zoledronic acid has been adopted as a standard option in hormone-refractory prostate cancer with bone metastasis. $^{5}$

RCC will likely be one of the most sensitive cancers to bone resorption inhibition therapy. In a retrospective subset analysis of 74 patients with RCC enrolled in a multicenter, randomized, placebo-controlled study, zoledronic acid was found to significantly reduce the proportion of patients with an SRE (37\% vs 74\% for placebo; $P=0.015){ }^{7}$ Similarly, zoledronic acid significantly reduced the mean skeletal morbidity rate ( 2.68 vs 3.38 for placebo; $P=0.014$ ) and extended the time to the first event (median not reached vs 72 days for placebo; $P=0.006) .{ }^{7}$ The median time to progression of bone lesions was significantly longer for patients treated with zoledronic acid ( $P=0.014$ vs placebo). Although there was no statistical significance compared to 
placebo, the median overall survival showed a trend toward favoring zoledronic acid (295 days for the $4 \mathrm{mg}$ zoledronic acid group vs 216 days for the placebo group; $P=0.179){ }^{7}$ These results suggest that zoledronic acid not only decreases SREs, but also improves survival in patients with bone metastatic RCC.

In the context of urothelial cancer, a prospective, randomized, placebo-controlled trial in patients with bladder cancer metastatic to bone was recently reported. ${ }^{58}$ Compared to patients receiving placebo, those receiving zoledronic acid had a lower mean incidence of SREs (2.1 vs 0.95, respectively), and zoledronic acid prolonged the median time to first SRE compared to placebo (16 vs 8 weeks, respectively).$^{58}$ Multiple event analysis of SREs revealed that zoledronic acid decreased the risk of SRE development by $59 \%$ (hazard ratio [HR], 0.413). Zoledronic acid also increased the 1-year survival rate compared to placebo ( $36.3 \%$ vs $0 \%$, respectively). ${ }^{58}$ The investigators concluded that zoledronic acid therapy decreased the incidence of SREs and improved the 1-year survival rate of patients with bone metastases from bladder cancer, potentially through its anticancer activity. ${ }^{58}$

In addition to clinical trials using zoledronic acid, we previously used a mouse model to demonstrate the possibility to target osteoclasts to treat RCC and urothelial cancers. ${ }^{59-61}$ The first study showed that minodronic acid (also known as YM529), another third-generation bisphosphonate, had anticancer activity and synergistically augmented interferon-induced growth inhibition in vitro and in vivo. ${ }^{59}$ The second and third studies established luciferase-labeled human RCC and urothelial cancer cell models to investigate the inhibition of osteoclasts and of bone metastasis by minodronic acid in vivo. ${ }^{60}$ Minodronic acid administered systemically successfully showed significant anticancer efficacy in luciferase-labeled urothelial cancer cell bone metastases monitored using an in vivo imaging system. ${ }^{60}$ In addition, we demonstrated that prevention of osteoclast activity and/or maturation could lead inhibition of the growth of luciferase-labeled human RCC cells in a bone metastatic mouse model. ${ }^{61}$ Therefore, prevention of osteoclast genesis and function is an attractive therapeutic strategy in RCC and urothelial cancer bone metastasis.

\section{In vitro and in vivo preclinical anticancer activity of denosumab}

Denosumab inhibits the maturation of osteoclasts by binding to and inhibiting RANKL. As with zoledronic acid, the anti-SRE effect of denosumab is considered indirect via the inhibition of osteoclast function; however, some in vitro and in vivo studies have demonstrated a possible direct anticancer effect.

As discussed above, RANKL is a critical osteoclast differentiation factor that is highly expressed in the bone marrow environment. Besides indirect activity via prevention of osteoclast function, denosumab was demonstrated to act directly on RANK-expressing cancer cells, including breast, prostate and melanoma cells. ${ }^{62}$ Jones et al demonstrated that RANKL plays an important role in the cell migration and tissue-specific metastatic behavior of cancer cells. They found expression of the receptor RANK on various cancer cells that preferentially metastasize to bone. ${ }^{62}$ In addition, RANKL triggers cytoskeletal changes and migration in several RANK-expressing cancer cells. Moreover, the authors demonstrated that the inhibition of the RANKL/ RANK signal by OPG in vivo markedly and selectively reduces bone metastasis. ${ }^{62}$

Gonzalez-Suarez et al demonstrated that RANK and RANKL are expressed in normal, premalignant, and neoplastic mammary epithelium. In addition, in complementary gain-offunction studies in mouse mammary tumor virus (MMTV)RANK transgenic mice, accelerated preneoplasia and increased mammary tumor formation was observed after multiparity or treatment with carcinogen and hormone (progesterone). ${ }^{63}$ In loss-of-function approaches, selective pharmacological inhibition of RANKL attenuated mammary tumor development, not only in hormone- and carcinogen-treated MMTV-RANK and wild-type mice, but also in the MMTV-neu transgenic spontaneous tumor model. ${ }^{63}$ The authors concluded that the RANK/RANKL pathway directly contributes to mammary carcinogenesis. ${ }^{63}$ These preclinical studies suggest a possible direct anticancer effect of denosumab.

In addition, Miller et al showed the potential clinical utility of denosumab with docetaxel in castration-resistant prostate cancer. ${ }^{64}$ They demonstrated that the RANKL inhibitor OPG-Fc alone reduced bone resorption $(P<0.001$ vs PBS), inhibited progression of established osteolytic lesions, and reduced tumor area $\left(P<0.0001\right.$ vs PBS) ${ }^{64}$ In addition, combination of the RANKL inhibitor OPG-Fc and docetaxel markedly suppressed skeletal tumor burden $(P=0.0005)$ and increased median survival time by $16.7 \%(P=0.0385)$ compared to docetaxel alone in a murine model of prostate cancer bone metastasis. ${ }^{64}$

\section{Denosumab, a new option in the treatment of urological cancer bone metastasis}

Three main Phase III clinical studies have been published in prostate cancer. The first study was conducted to evaluate 
Table 2 Summary of denosumab Phase III clinical trials in prostate cancer

\begin{tabular}{|c|c|c|c|c|c|}
\hline Patients & Denosumab & Control & $\mathbf{n}$ & Purpose & Results \\
\hline $\begin{array}{l}\text { HSPC without metastasis } \\
\text { (under } \mathrm{ADT}^{3} \text { ) }\end{array}$ & $60 \mathrm{mg} / 6$ months & Placebo & 1468 & $\begin{array}{l}\text { Prevention } \\
\text { of BMD reduction }\end{array}$ & $\begin{array}{l}\text { Denosumab was associated } \\
\text { with increased BMD }\end{array}$ \\
\hline CRPC without bone metastasis & 120 mg/4 weeks & Placebo & 1432 & $\begin{array}{l}\text { Prevention } \\
\text { of bone metastasis }\end{array}$ & $\begin{array}{l}\text { Denosumab increased bone } \\
\text { metastasis-free survival }\end{array}$ \\
\hline CPRC with bone metastasis & 120 mg/4 weeks & Zoledronic acid & 1904 & $\begin{array}{l}\text { Prevention } \\
\text { of SRE }\end{array}$ & $\begin{array}{l}\text { Denosumab was better than } \\
\text { zoledronic acid for prevention of SRE }\end{array}$ \\
\hline
\end{tabular}

Abbreviations: ADT, androgen-sensitive prostate cancer; BMD, bone mineral density; CRPC, castration-resistant prostate cancer; HSPC, hormone-sensitive prostate cancer; $n$, number of patients; SRE, skeletal-related events.

the effect of denosumab on BMD and fractures in men receiving ADT. ${ }^{65}$ The second study compared denosumab to zoledronic acid for the prevention of SREs in men with bone metastases from castration-resistant prostate cancer. ${ }^{66}$ The third study assessed denosumab for prevention of bone metastasis or death in nonmetastatic castration-resistant prostate cancer. ${ }^{67}$ The purpose and results of these studies are summarized in Table 2.

In the first study, which was double-blind and multicenter, patients receiving ADT for nonmetastatic prostate cancer were randomly assigned to receive denosumab at a dose of $60 \mathrm{mg}$ subcutaneously every 6 months or placebo (734 patients in each group). ${ }^{65}$ Denosumab therapy was associated with significant increases in BMD at the lumbar spine, total hip, femoral neck, and distal third of the radius at all time points. ${ }^{66}$ Moreover, patients who received denosumab had a decreased incidence of new vertebral fractures at 36 months ( $1.5 \%$ vs $3.9 \%$ with placebo) (relative risk, 0.38 ; $P=0.006){ }^{65}$

In the second study, men with castration-resistant prostate cancer and no previous exposure to intravenous bisphosphonate were enrolled at 342 centers in 39 countries; 1904 patients were randomly assigned to $120 \mathrm{mg}$ subcutaneous denosumab $(\mathrm{n}=950)$ or $4 \mathrm{mg}$ intravenous zoledronic acid ( $\mathrm{n}=951) .{ }^{66}$ The median time to first on-study SRE was 20.7 months with denosumab compared to 17.1 months with zoledronic acid (HR, 0.82, $P=0.0002$ for noninferiority; $P=0.008$ for superiority). ${ }^{66}$ Although more events of hypocalcaemia occurred in the denosumab group (13\%) than in the zoledronic acid group $(6 \% ; P<0.0001)$, denosumab seemed to not be worse than zoledronic acid for preventing SREs and potentially represents a novel treatment option in men with bone metastases from castration-resistant prostate cancer. ${ }^{66}$

In the third study, which was double-blind, randomized, and placebo-controlled, men with nonmetastatic castrationresistant prostate cancer at high risk of bone metastasis were enrolled at 319 centers in 30 countries; 1432 patients were randomly assigned to treatment groups (716 denosumab, 716 placebo) ${ }^{67}$ Denosumab significantly increased bone metastasis-free survival by a median of 4.2 months compared to placebo (median 29.5 vs 25.2 months; HR, $0.85 ; P=0.028) \cdot{ }^{67}$ Denosumab also significantly delayed the time to first bone metastasis (33.2 vs 29.5 months; HR, 0.84; $P=0.032$ ); however, the overall survival did not differ between the groups (denosumab, 43.9 vs placebo, 44.8 months; HR, $1.01 ; P=0.91) \cdot{ }^{67}$ Although the rates of adverse events and serious adverse events were similar in both groups, $33(5 \%)$ patients on denosumab developed osteonecrosis of the jaw (none on placebo) and $12(2 \%)$ patients on denosumab developed hypocalcemia $(<1 \%$ on placebo). ${ }^{67}$

There is currently no clinical report describing the efficacy of denosumab in RCC or urothelial cancer; however, the anti-bone resorption agent zoledronic acid demonstrated good clinical and preclinical efficacy in these diseases. . $^{5,858-64}$ Decreased SREs were associated with a potential survival benefit in patients with metastatic RCC and bladder cancer in bone metastatic RCC and bladder cancer. Zoledronic acid has the potential to induce renal impairment, and therefore requires that renal function be monitored and sometimes doses adjusted or withheld, particularly in patients with RCC or upper urinary tract urothelial cancer who often have a single functional kidney. In contrast, denosumab has no renal toxicity and is emerging as a key therapeutic option for the treatment of bone metastases from urological cancers.

\section{Conclusions and future directions}

Accumulated evidence suggests that the inhibition of bone resorption is a promising anticancer therapy without severe adverse effects. Until now, zoledronic acid was the only approved agent inhibiting bone resorption. Denosumab is a novel and attractive option for the treatment of bone metastases from urological cancers. In prostate cancer, the addition of the novel hormonal agents abiraterone acetate, MDV-3100, and TAK700 to the therapeutic armamentarium 
will lead to greater reliance on ADT, suggesting that the adverse events associated with ADT may become a greater clinical problem in the future. As a result, a more careful assessment and monitoring of SRE and more anti-bone resorption therapeutic options will be needed. Currently, the optimum therapy for metastatic bone disease as well as anti-bone resorption remains uncertain. In order to clarify this issue, accumulated clinical practice will be necessary.

\section{Acknowledgments}

The work was partly supported by the Smoking Research Foundation, the Takeda Science Foundation, and Grants-inAid for Scientific Research from the Ministry of Education, Culture, Sports, Science and Technology, Japan.

\section{Disclosure}

The authors report no conflict of interest in this work.

\section{References}

1. Roodman GD. Mechanisms of bone metastasis. N Engl J Med. 2004; 350(16):1655-1664

2. Onishi T, Hayashi N, Theriault RL, Hortobagyi GN, Ueno NT. Future directions of bone-targeted therapy for metastatic breast cancer. Nat Rev Clin Oncol. 2010;7(11):641-651.

3. Morgan SC, Parker CC. Local treatment of metastatic cancer-killing the seed or disturbing the soil? Nat Rev Clin Oncol. 2011;8(8):504-506.

4. Coleman RE. Bisphosphonates: clinical experience. Oncologist. 2004; 9 Suppl 4:14-27.

5. Saad F, Gleason DM, Murray R, T et al. Zoledronic Acid Prostate Cancer Study Group. A randomized, placebo-controlled trial of zoledronic acid in patients with hormone-refractory metastatic prostate carcinoma. J Natl Cancer Inst. 2002;94(19):1458-1468.

6. Rosen LS, Gordon D, Tchekmedyian S, et al. Zoledronic acid versus placebo in the treatment of skeletal metastases in patients with lung cancer and other solid tumors: a phase III, double-blind, randomized trial - the Zoledronic Acid Lung Cancer and Other Solid Tumors Study Group. J Clin Oncol. 2003;21(16):3150-3157.

7. Lipton A, Colombo-Berra A, Bukowski RM, Rosen L, Zheng M, Urbanowitz G. Skeletal complications in patients with bone metastases from renal cell carcinoma and therapeutic benefits of zoledronic acid. Clin Cancer Res. 2004;10(18 Pt 2):6397S-6403S.

8. Kohno N, Aogi K, Minami H, et al. Zoledronic acid significantly reduces skeletal complications compared with placebo in Japanese women with bone metastases from breast cancer: a randomized, placebo-controlled trial. J Clin Oncol. 2005;23(15):3314-3321.

9. Wittrant Y, Théoleyre S, Chipoy C, et al. RANKL/RANK/OPG: new therapeutic targets in bone tumours and associated osteolysis. Biochim Biophys Acta. 2004;1704(2):49-57.

10. Hofbauer LC, Schoppet M. Clinical implications of the osteoprotegerin/ RANKL/RANK system for bone and vascular diseases. JAMA. 2004; 292(4):490-495.

11. Body JJ, Facon T, Coleman RE, et al. A study of the biological receptor activator of nuclear factor-kappaB ligand inhibitor, denosumab, in patients with multiple myeloma or bone metastases from breast cancer. Clin Cancer Res. 2006;12(4):1221-1228.

12. Henry DH, Costa L, Goldwasser F, et al. Randomized, double-blind study of denosumab versus zoledronic acid in the treatment of bone metastases in patients with advanced cancer (excluding breast and prostate cancer) or multiple myeloma. J Clin Oncol. 2011;29(9):1125-1132.
13. Srinivasan $R$, Linehan WM. Treatment of advanced renal cell carcinoma. In: Kavoussi LR, Novick AC, Partin AW, Peters CA, Wein AJ, editors. Campbell-Walsh Urology. 10th ed. New York, NY: Saunders; 2011:1475-1491.

14. Ljungberg B, Hanbury DC, Kuczyk MA, et al; European Association of Urology Guideline Group for renal cell carcinoma. Renal cell carcinoma guideline. Eur Urol. 2007;51(6):1502-1510.

15. Yuasa T, Urakami S, Yamamoto $\mathrm{S}$, et al. Treatment outcome and prognostic factors of the patients with renal cell cancer bone metastasis. Clin Exp Metastasis. 2011;28(4):405-411.

16. Lipton A. Management of Bone Metastasis in patients with Renal Cell Carcinoma and Other Malignancies of the Genitourinary Tract. In: Kantoff P, Saad F, Smith MR, editors. Management of Skeletal Complications of Prostate Cancer and Other Genitourinary Malignancies. Philadelphia, PA: FA Davis Co; 2004:207-234.

17. Zekri J, Ahmed N, Coleman RE, Hancock BW. The skeletal metastatic complications of renal cell carcinoma. Int J Oncol. 2001;19(2): 379-382.

18. Naito S, Yamamoto N, Takayama T, et al. Prognosis of Japanese metastatic renal cell carcinoma patients in the cytokine era: a cooperative group report of 1463 patients. Eur Urol. 2010;57:317-325.

19. Kuczyk MA, Anastasiadis AG, Zimmermann R, Merseburger AS, Corvin S, Stenzi A. Current aspects of the surgical management of organ-confined, metastatic, and recurrent renal cell cancer. BJU Int. 2005;96(5):721-727; quiz i-ii.

20. Toyoda Y, Shinohara N, Harabayashi T, et al. Survival and prognostic classification of patients with metastatic renal cell carcinoma of bone. Eur Urol. 2007;52(1):163-168.

21. Motzer RJ, Bacik J, Murphy BA, Russo P, Mazumdar M. Interferon-alfa as a comparative treatment for clinical trials of new therapies against advanced renal cell carcinoma. J Clin Oncol. 2002;20(1):289-296.

22. Siegel R, Naishadham D, Jemal A. Cancer statistics, 2012. CA Cancer J Clin. 2012;62(1):10-29.

23. Lerner SP, Sternberg CN. Management of metastatic and invasive bladder cancer In: Kavoussi LR, Novick AC, Partin AW, Peters CA, Wein AJ, editors. Campbell-Walsh Urology. 10th ed. New York, NY: Saunders; 2011:2355-2374.

24. Gee J, Sabichi AL, Grossman HB. Chemoprevention of superficial bladder cancer. Crit Rev Oncol Hematol. 2002;43(3):277-286.

25. StenzlA, Cowan NC, De Santis M, et al; European Association of Urology (EAU). Treatment of muscle-invasive and metastatic bladder cancer: update of the EAU guidelines. Eur Urol. 2011;59(6):1009-1018.

26. Dreicer R. Locally advanced and metastatic bladder cancer. Curr Treat Options Oncol. 2001;2(5):431-436.

27. Babaian RJ, Johnson DE, Llamas L, Ayala AG. Metastases from transitional cell carcinoma of urinary bladder. Urology. 1980;16(2): $142-144$.

28. Hussain SA, James ND. The systemic treatment of advanced and metastatic bladder cancer. Lancet Oncol. 2003;4(8):489-497.

29. Bellmunt J, Albanell J, Paz-Ares L, et al; Spanish Oncology Genitourinary Group. Pretreatment prognostic factors for survival in patients with advanced urothelial tumors treated in a phase I/II trial with paclitaxel, cisplatin, and gemcitabine. Cancer. 2002;95(4):751-757.

30. Tsukamoto T, Yonese J, Ohkubo Y, Fukui I. Phase I/II study of a combined gemcitabine, etoposide, and cisplatin chemotherapy regimen for metastatic urothelial carcinoma. Cancer. 2006;106(11):2363-2368.

31. Nelson JB. Hormonal therapy of prostate cancer. In: Kavoussi LR, Novick AC, Partin AW, Peters CA, Wein AJ, editors. Campbell-Walsh Urology. 10th ed. New York, NY: Saunders; 2011:2934-2953.

32. Johansson JE, Andrén O, Andersson SO, et al. Natural history of early, localized prostate cancer. JAMA. 2004;291(22):2713-2719.

33. Scher HI, Halabi S, Tannock I, et al; Prostate Cancer Clinical Trials Working Group. Design and end points of clinical trials for patients with progressive prostate cancer and castrate levels of testosterone: recommendations of the Prostate Cancer Clinical Trials Working Group. J Clin Oncol. 2008;26(7):1148-1159. 
34. Petrylak DP, Tangen CM, Hussain MH, et al. Docetaxel and estramustine compared with mitoxantrone and prednisone for advanced refractory prostate cancer. $N$ Engl J Med. 2004;351(15):1513-1520.

35. Tannock IF, de Wit R, Berry WR, et al; TAX 327 Investigators. Docetaxel plus prednisone or mitoxantrone plus prednisone for advanced prostate cancer. N Engl J Med. 2004;351(15):1502-1512.

36. Yuasa T, Kimura S, Ashihara E, Habuchi T, Maekawa T. Zoledronic acid - a multiplicity of anti-cancer action. Curr Med Chem. 2007;14(20): 2126-2135.

37. Kimura S, Kuroda J, Segawa H, et al. Antiproliferative efficacy of the third-generation bisphosphonate, zoledronic acid, combined with other anticancer drugs in leukemic cell lines. Int J Hematol. 2004;79(1):37-43.

38. Matsumoto S, Kimura S, Segawa S, et al. Efficacy of the third-generation bisphosphonate, zoledronic acid alone and combined with anti-cancer agents against small cell lung cancer cell lines. Lung Cancer. 2005;47: 31-39.

39. Neville-Webbe HL, Evans CA, Coleman RE, Holen I. Mechanisms of the synergistic interaction between the bisphosphonate zoledronic acid and the chemotherapy agent paclitaxel in breast cancer cells in vitro. Tumour Biol. 2006;27(2):92-103.

40. Jagdev SP, Coleman RE, Shipman CM, Rostami-H A, Croucher PI. The bisphosphonate, zoledronic acid, induces apoptosis of breast cancer cells: evidence for synergy with paclitaxel. Br J Cancer. 2001;84(8): 1126-1134.

41. Smith MR. Osteoporosis and obesity in men receiving hormone therapy for prostate cancer. J Urol. 2004;172(5 Pt 2):S52-S56.

42. Wang W, Yuasa T, Tsuchiya N, et al. Bone mineral density in Japanese prostate cancer patients under androgen-deprivation therapy. Endocr Relat Cancer. 2008;15(4):943-952.

43. Yuasa T, Maita S, Tsuchiya N, et al. Relationship between bone mineral density and androgen-deprivation therapy in Japanese prostate cancer patients. Urology. 2010;75(5):1131-1137.

44. Huggins C, Hodges VC. Studies on prostate cancer: I. The effect of castration, of estrogen and of androgen injection on serum phosphatases in metastatic carcinoma of the prostate. Cancer Res. 1941;1:293-297.

45. Cooperberg MR, Grossfeld GD, Lubeck DP, Carroll PR. National practice patterns and time trends in androgen ablation for localized prostate cancer. J Natl Cancer Inst. 2003;95(13):981-989.

46. Sharifi N, Gulley JL, Dahut WL. Androgen deprivation therapy for prostate cancer. JAMA. 2005;294(2):238-244.

47. Higano CS. Side effects of androgen deprivation therapy: monitoring and minimizing toxicity. Urology. 2003;61(2 Suppl 1):32-38.

48. Shahinian VB, Kuo YF, Freeman JL, Goodwin JS. Risk of fracture after androgen deprivation for prostate cancer. N Engl J Med. 2005;352(2): 154-164.

49. Greenspan SL, Coates P, Sereika SM, Nelson JB, Trump DL, Resnick NM. Bone loss after initiation of androgen deprivation therapy in patients with prostate cancer. J Clin Endocrinol Metab. 2005;90(12): 6410-6417.

50. Bruder JM, Ma JZ, Basler JW, Welch MD. Prevalence of osteopenia and osteoporosis by central and peripheral bone mineral density in men with prostate cancer during androgen-deprivation therapy. Urology. 2006;67(1):152-155.

51. Morote J, Morin JP, Orsola A, et al. Prevalence of osteoporosis during long-term androgen deprivation therapy in patients with prostate cancer. Urology. 2007;69(3):500-504.
52. Morote J, Orsola A, Abascal JM, et al. Bone mineral density changes in patients with prostate cancer during the first 2 years of androgen suppression. J Urol. 2007;175(5):1679-1683.

53. Oefelein MG, Ricchiuti VS, Conrad PW, et al. Clinical predictors of androgen-independent prostate cancer and survival in the prostatespecific antigen era. Urology. 2002;60(1):120-124.

54. Mikami S, Katsube K, Oya M, et al. Increased RANKL expression is related to tumour migration and metastasis of renal cell carcinomas. J Pathol. 2009;218(4):530-539.

55. Chen G, Sircar K, Aprikian A, Potti A, Goltzman D, Rabbani SA. Expression of RANKL/RANK/OPG in primary and metastatic human prostate cancer as markers of disease stage and functional regulation. Cancer. 2006;107(2):289-298.

56. Narita N, Yuasa T, Tsuchiya N, et al. A genetic polymorphism of the osteoprotegerin gene is associated with an increased risk of advanced prostate cancer. BMC Cancer. 2008;8:224.

57. Fleisch H. Development of bisphosphonates. Breast Cancer Res. 2002; $4(1): 30-34$.

58. Zaghloul MS, Boutrus R, El-Hossieny H, KaderYA, El-Attar I, Nazmy M. A prospective, randomized, placebo-controlled trial of zoledronic acid in bony metastatic bladder cancer. Int J Clin Oncol. 2010;15(4): 382-389.

59. Yuasa T, Nogawa M, Kimura S, et al. A third-generation bisphosphonate, minodronic acid (YM529), augments the interferon $\alpha \beta$-mediated inhibition of renal cell cancer cell growth both in vitro and in vivo. Clin Cancer Res. 2005;11(2 Pt 1):853-859.

60. Sato K, Yuasa T, Nogawa M, et al. A third-generation bisphosphonate, minodronic acid (YM529), successfully prevented the growth of bladder cancer in vitro and in vivo. Br J Cancer. 2006;95(10):1354-1361.

61. Maita S, Yuasa T, Tsuchiya N, et al. Antitumor effect of sunitinib against skeletal metastatic renal cell carcinoma through inhibition of osteoclast function. Int J Cancer. 2012;130(3):677-684.

62. Jones DH, Nakashima T, Sanchez OH, et al. Regulation of cancer cell migration and bone metastasis by RANKL. Nature. 2006;440(7084): 692-696.

63. Gonzalez-Suarez E, Jacob AP, Jones J, et al. RANK ligand mediates progestin-induced mammary epithelial proliferation and carcinogenesis. Nature. 2010;468(7320):103-107.

64. Miller RE, Roudier M, Jones J, Armstrong A, Canon J, Dougall WC. RANK ligand inhibition plus docetaxel improves survival and reduces tumor burden in a murine model of prostate cancer bone metastasis. Mol Cancer Ther. 2008;7(7):2160-2169.

65. Smith MR, Egerdie B, Hernández Toriz N, et al; Denosumab HALT Prostate Cancer Study Group. Denosumab in men receiving androgendeprivation therapy for prostate cancer. $N$ Engl J Med. 2009;361(8): $745-755$.

66. Fizazi K, Carducci M, Smith M, et al. Denosumab versus zoledronic acid for treatment of bone metastases in men with castration-resistant prostate cancer: a randomised, double-blind study. Lancet. 2011, 377(9768):813-822.

67. Smith MR, Saad F, Coleman R, et al. Denosumab and bone-metastasisfree survival in men with castration-resistant prostate cancer: results of a phase 3, randomised, placebo-controlled trial. Lancet. 2012;379(9810): 39-46.
OncoTargets and Therapy

\section{Publish your work in this journal}

OncoTargets and Therapy is an international, peer-reviewed, open access journal focusing on the pathological basis of all cancers, potential targets for therapy and treatment protocols employed to improve the management of cancer patients. The journal also focuses on the impact of management programs and new therapeutic agents and protocols on

\section{Dovepress}

patient perspectives such as quality of life, adherence and satisfaction. The manuscript management system is completely online and includes a very quick and fair peer-review system, which is all easy to use. Visit http://www.dovepress.com/testimonials.php to read real quotes from published authors. 